\title{
APPLICATION OF UNDERWATER LASER SCANNING FOR SEAFLOOR SHELL FRAGMENTS CHARACTERIZATION
}

\author{
Chau-Chang Wang \\ Institute of Applied Marine Physics and Undersea Technology, National Sun Yat-sen University, Kaohsiung 804, \\ Taiwan, R.O.C, chauwang@mail.nsysu.edu.tw \\ Dajun Tang \\ Applied Physics Lab, University of Washington, Seattle, WA 98105 USA.
}

Follow this and additional works at: https://jmstt.ntou.edu.tw/journal

Part of the Engineering Commons

\section{Recommended Citation}

Wang, Chau-Chang and Tang, Dajun (2012) "APPLICATION OF UNDERWATER LASER SCANNING FOR SEAFLOOR SHELL FRAGMENTS CHARACTERIZATION," Journal of Marine Science and Technology. Vol. 20: Iss. 1, Article 12. DOI: $10.51400 / 2709-6998.2427$

Available at: https://jmstt.ntou.edu.tw/journal/vol20/iss1/12

This Research Article is brought to you for free and open access by Journal of Marine Science and Technology. It has been accepted for inclusion in Journal of Marine Science and Technology by an authorized editor of Journal of Marine Science and Technology. 


\section{APPLICATION OF UNDERWATER LASER SCANNING FOR SEAFLOOR SHELL}

FRAGMENTS CHARACTERIZATION

\section{Acknowledgements}

The laser scanner development was supported by the Taiwan National Science Council (92-2611-E-110-005-CCS), and the Asian Pacific Ocean Research Center, National Sun Yat-sen University; instrument field trials were supported by the Office of Naval Research Ocean Acoustics Program. We thank Po-Chi Chen and Min-Wei Hung at IUT, NSYSU for their technical contribution, and the APL-UW technical staff for the at-sea support. 


\title{
APPLICATION OF UNDERWATER LASER SCANNING FOR SEAFLOOR SHELL FRAGMENTS CHARACTERIZATION
}

\author{
Chau-Chang Wang ${ }^{1}$ and Dajun Tang ${ }^{2}$
}

Key words: volume scattering, seafloor, shells, laser scanning, statistics.

\begin{abstract}
Two features required for modeling high-frequency acoustic scattering from seafloor are roughness and discrete objects distributed on the seafloor. A laser scanner was deployed to acquire fine-scale bottom roughness off the coast of New Jersey in 2006. On the bathymetry map, it was found that the sites were covered by shell fragments. Cross-comparison between the laser reflection intensity and the bathymetry suggests that the shell fragments have a stronger reflection intensity than the seafloor. This phenomenon was confirmed by an indoor experiment on a simulated seafloor. An intensity-based algorithm was developed to detect shell fragments on the seafloor. The field data were analyzed by this method. Shell fragments visible on the bathymetry were detected along with smaller pieces which were not obvious on the bathymetry map. Preliminary analysis shows that the seafloor was covered by shell fragments (greater than $4 \mathrm{~mm}^{2}$ ) with an area coverage $6.80 \%$ and $9.82 \%$ for the two sites studied. The shell size probability density distribution function is well modeled by a power-law which implies the weathering of shells is from numerous processes acting on different scales. This method provides the sediment surface information over a larger area which is difficult to acquire by conventional sediment coring.
\end{abstract}

\section{INTRODUCTION}

Models of high-frequency $(100-500 \mathrm{kHz})$ acoustic scattering from the seafloor generally consider two mechanisms responsible for bottom backscatter - bottom roughness and volume heterogeneity. These models require environmental inputs, such as fine-scale roughness of the water/sediment interface, inhomogeneities in subbottom layers, and discrete

Paper submitted 04/16/10; revised 05/10/11; accepted 05/12/11. Author for correspondence: Chau-Chang Wang (e-mail: chauwang@mail.nsysu.edu.tw). ${ }^{I}$ Institute of Applied Marine Physics and Undersea Technology, National Sun Yat-sen University, Kaohsiung 804, Taiwan, R.O.C.

${ }^{2}$ Applied Physics Lab, University of Washington, Seattle, WA 98105 USA. object distribution on the interface $[2,6-10,12,13,15,17,19$, 22-24]. Roughness backscatter has received more attention both theoretically and experimentally $[9,10,12,17,19]$; these studies rely on methods to measure bottom roughness power spectra as an environmental input to backscatter models. A large collection of roughness data is available for different water depths and sediment types with several different measurement methods [11]. The measurement methods include analogue and digital stereo photography [1, 14, 16], laser scanning [3, 18] and sediment conductivity probe [2, 21]. Scattering from discrete objects both on and in the sediment has also been studied with considerable modeling efforts and some experimental work [6-9, 13, 15, 22, 24]. Stanton and Chu [20] report that shells' edges play an important role in the backscatter geometry of a laboratory-simulated shell-covered seafloor. However, because of the variety of volume scatterers and the difficulties associated with the measurement of their distributions, detailed model/data comparisons are few.

To carry out high-frequency backscatter experiments from discrete scatterers in the field, measurement methods must be developed to characterize the size and spatial distributions of these scatterers. Vertical distribution of discrete scatters can be obtained by coring, but this provides limited horizontal coverage due to the small diameters of the core tubes. Effective methods to acquire horizontal distributions of discrete scatterers are needed. Here, methods to measure shell distributions on the seafloor by a laser line scanner and the results of laboratory and field experiments are reported.

\section{FIELD MEASUREMENTS}

A Seafloor Laser Scanner (SLS) was developed to measure fine-scale bottom roughness at water depth up to two hundred meters. The system was deployed in the US Office of Naval Research-sponsored Shallow Water 2006 experiment (SW06) on the New Jersey shelf, at $80 \mathrm{~m}$ water depth. The working principles of the SLS and its deployments are reported by [25, 26]. Briefly, it is a structured-light-based system consisting of a water-proof laser line projector, a CCD camera, and a PC control unit (Fig. 1) [5]. The scanning head assembly maintains the relative position and orientation between the camera (Basler A102f CCD with $1388 \times 1038$ pixels) and the laser 


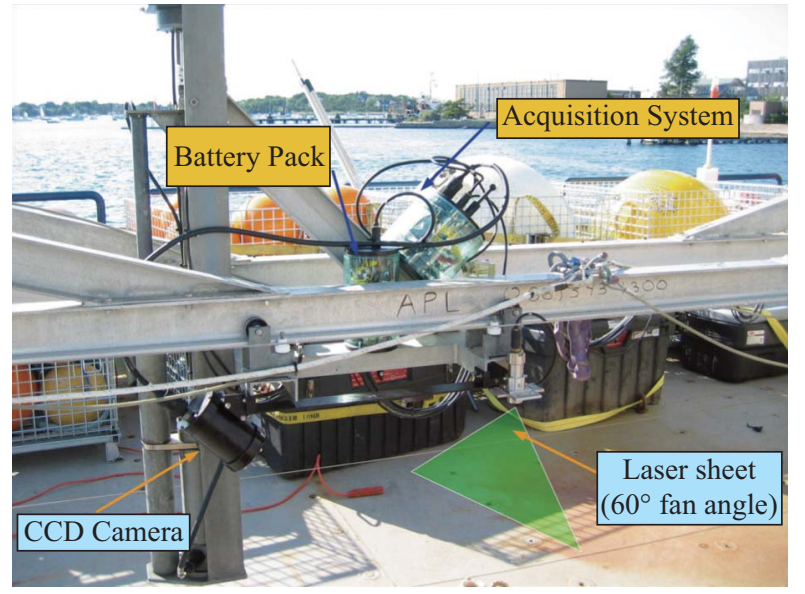

Fig. 1. Integration of SLS with IMP2. The laser is split to a sheet with $60^{\circ}$ fan angle to project on the seafloor for scanning. The laser sheet is perpendicular to the motion of the carriage.

line source. The laser wavelength is $650 \mathrm{~nm}$, and a cylindrical lens is placed at its tip to generate a $60^{\circ}$ fan angle. The scanning head assembly, mounted on the carriage of a conductivity probe called the In-situ Measurement of Porosity, 2nd Generation (IMP2) system [21], was kept roughly $75 \mathrm{~cm}$ above the seafloor to have an effective scanning swath of about $30 \mathrm{~cm}$. The CCD was tilted down to look at the laser reflection from the seafloor at a $30^{\circ}$ grazing angle. With this configuration, the optical resolution on the vertical scanning plane was 0.3 $\mathrm{mm}$. The resolution along the track direction depends on the ratio between the speed of the carriage $(2.3 \mathrm{~mm} / \mathrm{s})$ to the frame rate (6-7 frame/s) of the CCD camera, which is about 0.4 to 0.5 $\mathrm{mm}$ for this case. The carriage of IMP2 moved with a constant speed, the distance of an image frame from the initial image frame along the track was determined based on the frame acquisition time. In each image frame, the high-contrast pixels correspond to the reflection of the laser line from the seabed. With a calibrated camera, the pixels on the laser line are converted into the relief of the seafloor at the scan location [25]. The combined-system provides three dimensional bathymetry at sub-millimeter resolution covering an area $360 \mathrm{~cm}$ long and $30 \mathrm{~cm}$ wide (e.g., upper panel of Fig. 2). It is easy to identify scatterers such as starfishes, shells, and shell fragments distributed on the seafloor in the image. While the offset of the laser scanning strip provides the relief, the laser reflection intensity offers information of the material from which it is scattered. As shown in Fig. 3, the reflection intensity from a single scan exhibits large variations, which is likely due to the difference of reflectivity between sediment grains and the discrete objects. The laser reflection intensity data were processed to construct a reflectivity map for the same area as for the elevation map and is given in the lower panel of Fig. 2. This map is similar to the $3 \mathrm{D}$ bathymetry map, but the elevation is replaced by the intensity value. The shell pieces show as dents and bumps in the bathymetry image, but appear with more texture and brightness against the sandy back-

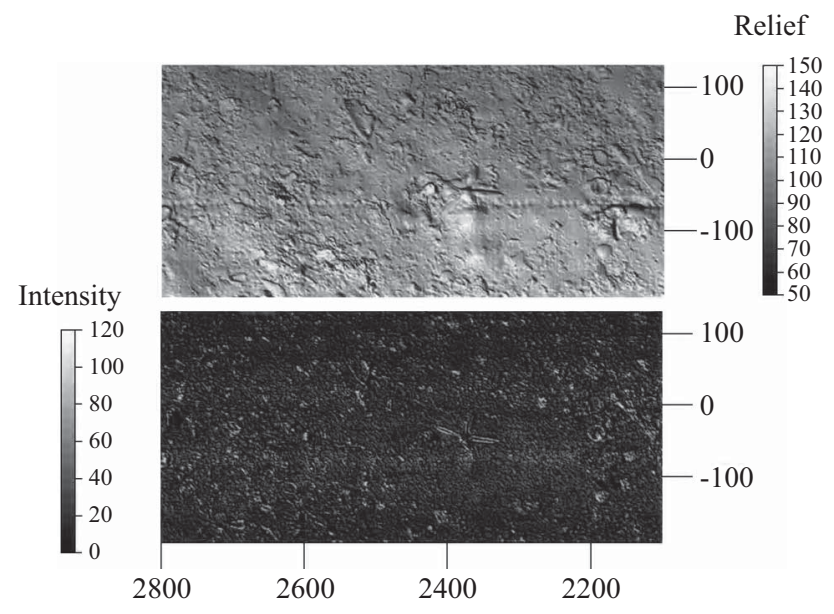

Fig. 2. Three-dimensional shaded-relief map of the seafloor roughness (top) and reflectivity map of the same area of seafloor (bottom). The regularly spaced line of marks in the top panel are left by the conductivity probe, which made its measurement prior to the laser scan. The marks are not visible in the reflectivity image. (All dimensions are in $\mathbf{m m}$ except for the reflection intensity.)
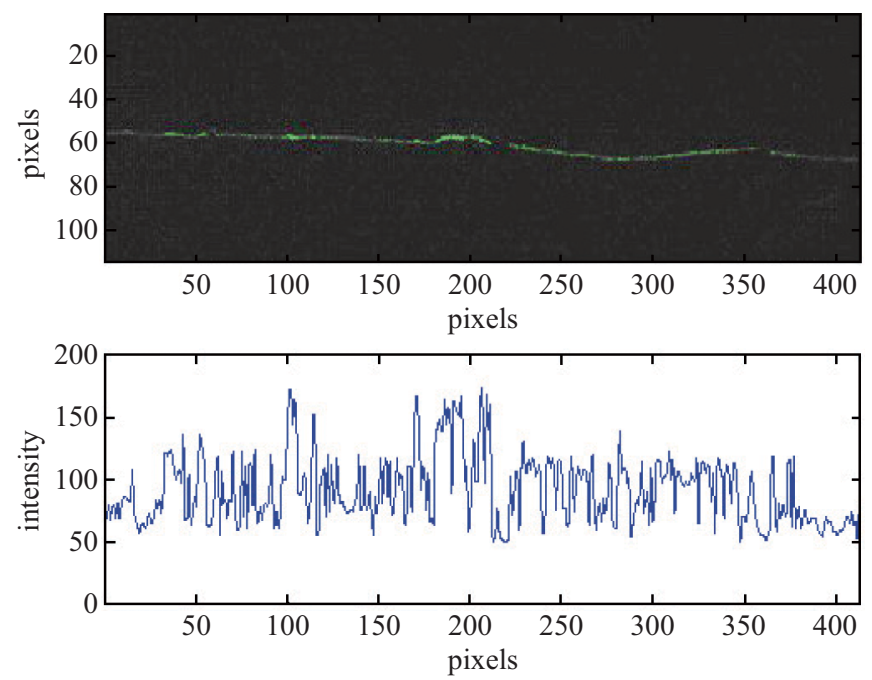

Fig. 3. A sample scanning frame. Reflection varies along the laser line for different textures of the seafloor (top panel). The corresponding intensity along the scan line is plotted for reference (bottom panel.)

ground in the reflectivity image. Some small pieces of shell fragments, not obvious in the bathymetry map, are identifiable in the reflectivity map.

The strong reflectivity contrast between discrete objects and the background offers the possibility of estimating the size and number distributions of inhomogeneous objects on the seafloor. The accompanying roughness result provides additional information on the shape and location of the shell pieces. Both the roughness measurement and shell distributions are necessary to model high-frequency backscatter. To assess whether reflectivity is a quantitative measure of shells on the seafloor, a calibration test was conducted. 


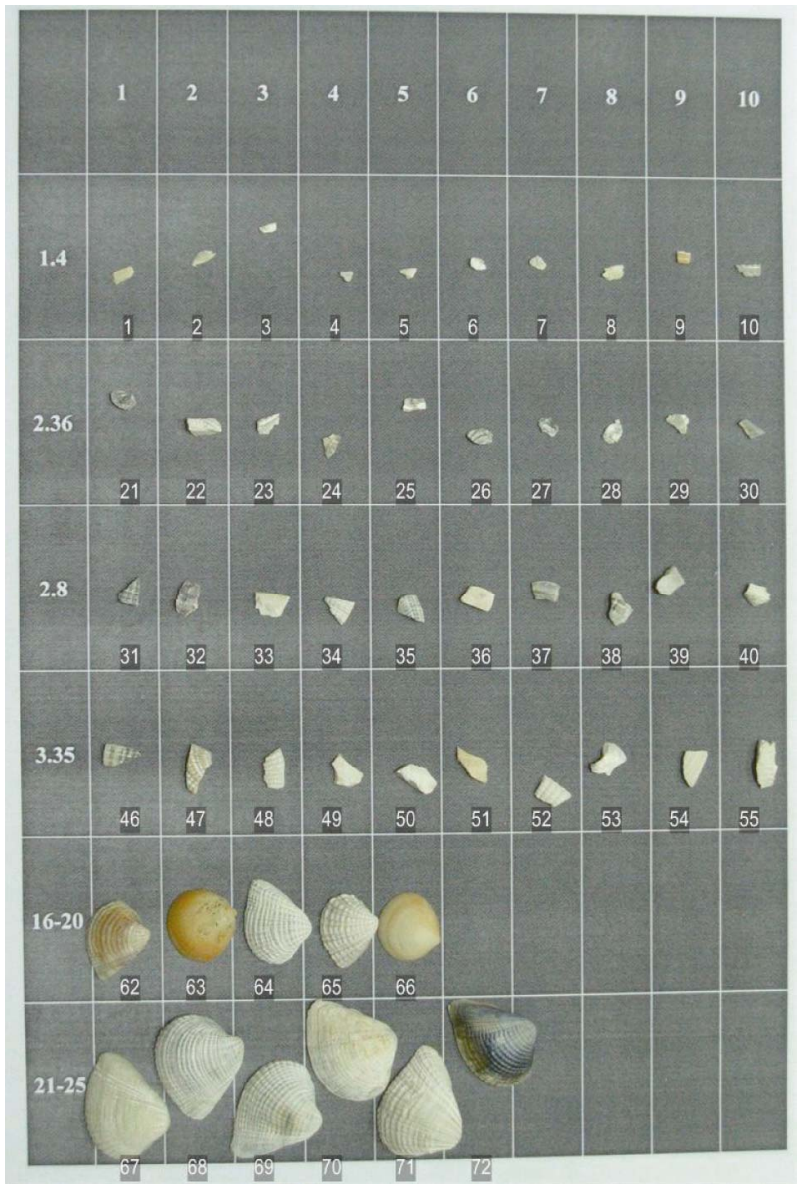

Fig. 4. Sample shell pieces used in the laboratory experiment. The numbers in the first column are the size $(\mathrm{mm})$ in the bin. The number adjacent to each shell pieces is a unique ID used in the random process of location generation.

Table 1. Number and size distribution of shells in the laboratory experiment.

\begin{tabular}{|c|c|c|c|c|c|c|}
\hline $\begin{array}{c}\text { Size } \\
(\mathrm{mm})\end{array}$ & $<1.4$ & $1.4-2.4$ & $2.4-2.8$ & $2.8-3.6$ & $16-20$ & $21-25$ \\
\hline $\begin{array}{c}\text { No. of } \\
\text { Shells }\end{array}$ & 20 & 10 & 15 & 16 & 5 & 6 \\
\hline
\end{tabular}

\section{LABORATORY MEASUREMENTS}

Beach sand was collected from which shells were sieved and sorted. The sand grain size was between 100-200 $\mu \mathrm{m}$. The shell fragments were categorized with sieves into six bins. A subset of shell pieces, about $10 \%$ from each bin, were used as samples in the laboratory experiment (Figs. 4 and 5). Shell fragments outnumbered complete shells (Table 1), owing to shell weathering by natural processes. The smallest pieces were indistinguishable from sand particles. The simulated seafloor was prepared by pouring the sand into a $30 \mathrm{~cm} \times 36$ $\mathrm{cm}$ tray, and raking smooth. Then shell fragments from each size bin (Table 1) were then placed on the sand surface. To

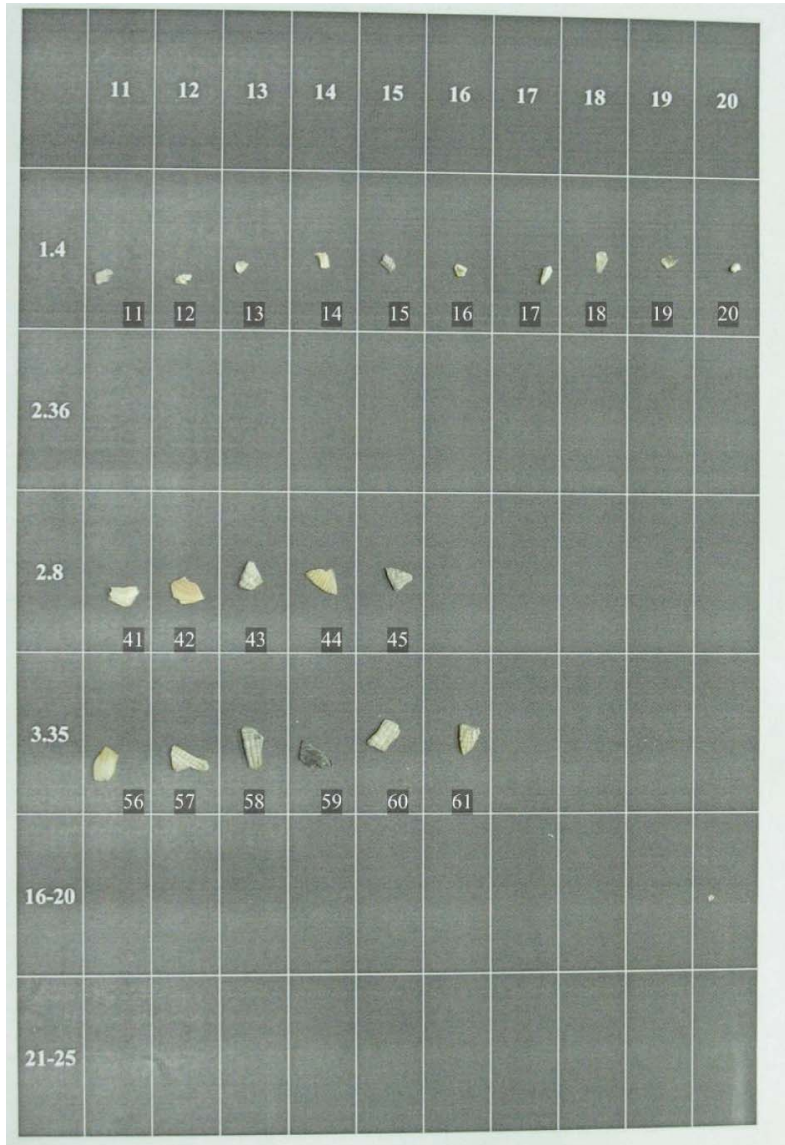

Fig. 5. Sample shell pieces in the laboratory experiment. The numbers in the first column are the size $(\mathrm{mm})$ in the bin. The number adjacent to each shell pieces is a unique ID used in the random process of location generation.

determine their ordering and location each shell was assigned a unique number (the number adjacent to the shell piece shown in Figs. 4 and 5), and the sand tray was divided into nine regions. One random number was generated to select a shell fragment from the list, and another random number was generated to decide in which region on the tray to place the shell fragment. Then the shell fragment was tossed to the designated region, mimicking a Poisson process. Altogether, 72 shell pieces were placed on the sand surface with this method. However, as the water filled the tank, some lighter fragments were floated away by capillary air bubbles, or sank into the sand. Eventually 67 shell pieces were placed properly on the sandy surface in the tray. The finished arrangement is shown in Fig. 6, where the same number tag as in Fig. 4 was place placed on the side of each fragment for cross-reference.

A small underwater linear track was made for the laboratory experiment. The laser scanner and linear track were set with the same configuration as the SLS and IMP2 except for a shorter track length. The water depth at the SW06 site was 80 $\mathrm{m}$, a low-light environment even during day time. The lab scanning was performed at night to simulate similar signalto-noise ratio. A reflection intensity map of the simulated 


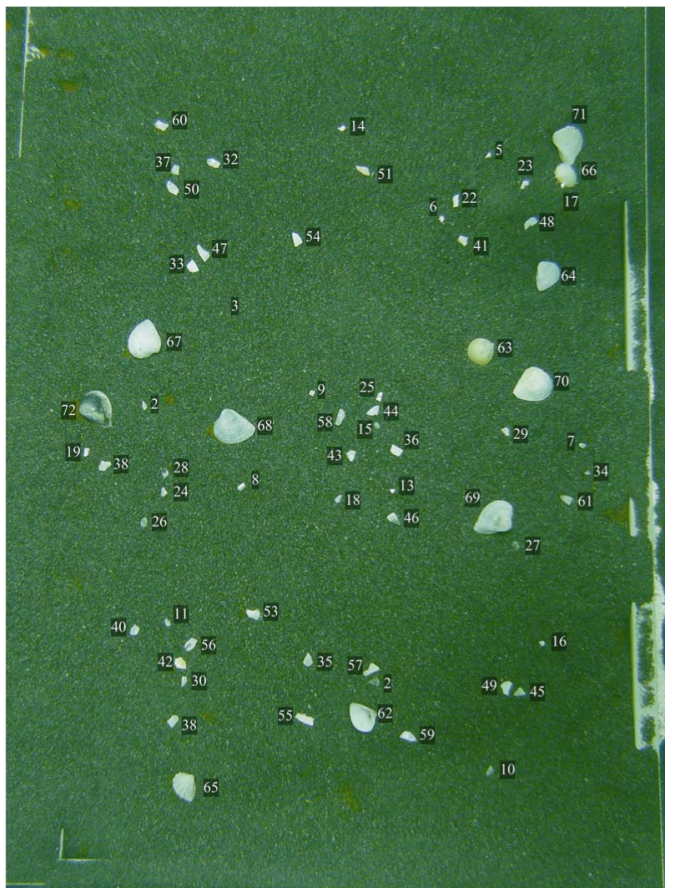

Fig. 6. Simulated seafloor covered with shell pieces for the laboratory experiment. Each shell piece is labeled with the number assigned in Figs. 4 and 5.

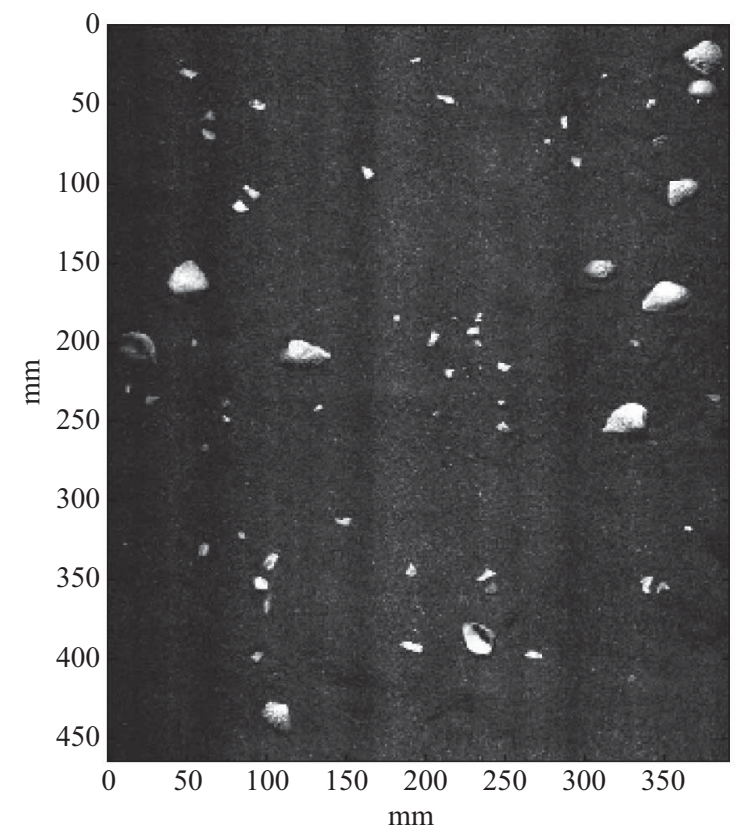

Fig. 7. Reflection intensity map of the simulated seafloor.

seafloor shows shell fragments as significantly brighter than the sandy background (Fig. 7). The reflection intensity map looks like a regular black-and-white photo, but its illumination is pixel-independent and uniform that is a property the regular photography does not have. This property also enables us to use a single threshold to distinguish shell pieces from their
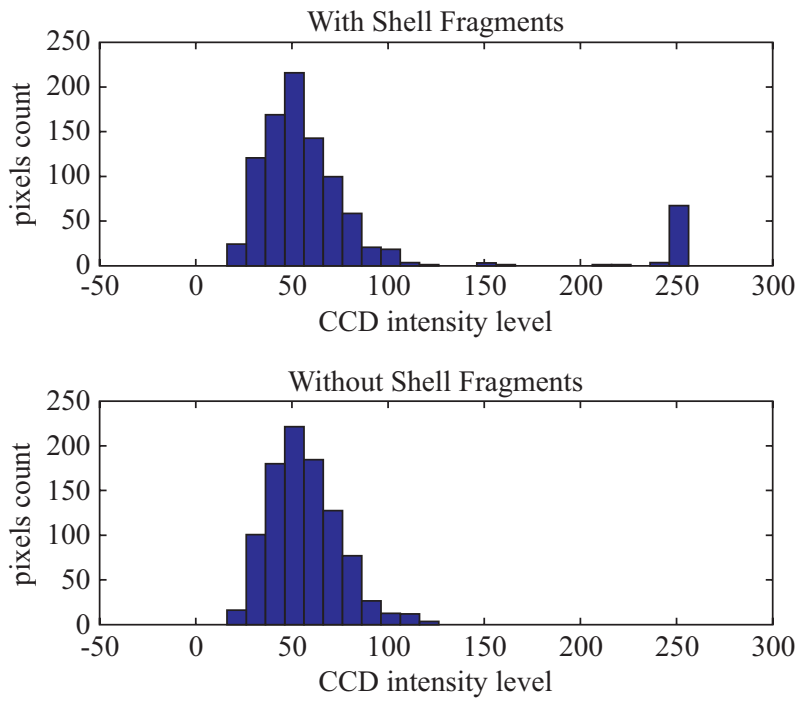

Fig. 8. Pixel intensity histogram comparison: with shells (upper panel) and without shells (lower panel). Noted that the main difference between the two cases is the existence of the saturated pixels in the shell covered seafloor.

background sediment. It is worth noticing that the sample shell fragments have several different colors, like limestone gray (no. 30), orange (no. 63) and dark charcoal (no. 72). However, the laboratory experiment shows that the colors of shells do not have significant difference in reflectivity.

Two scanning lines were selected: one with and one without shell fragments in the scene. Histograms of reflection intensities of pixels from the two scenes have distinctive patterns (Fig. 8). For the case without shell fragments, most of the pixels correspond to the seafloor and have relatively low intensity; their probability density function (PDF) is close to a Gaussian distribution centered at intensity 50. For the case with shell fragments there is an aggregation centered at intensity 50 and another narrowly distributed group near intensity 250 ( 255 is the saturation level of the CCD camera), which corresponds to the shell fragments. Because the two groups are well separated, the locations of shell fragments can be extracted by applying a threshold to the intensity data. An intensity level 120 was chosen to separate shells from sand for this case. When pixels exceeding the threshold were denoted with a red color superimposed on the raw intensity image (Fig. 9), all the shell fragments were identified successfully. This result confirms the applicability of using the laser reflection intensity to detect shell fragments as small as 3-4 $\mathrm{mm}^{2}$ which is a criterion to discern the shell fragments in the field data analysis.

\section{FIELD DATA ANALYSIS}

Two sets of laser scanning data were acquired at Site I $\left(39^{\circ}\right.$ $\left.01.5506^{\prime} \mathrm{N}, 73^{\circ} 02.7994^{\prime} \mathrm{W}\right)$ and Site II $\left(39^{\circ} 01.3559^{\prime} \mathrm{N}, 73^{\circ}\right.$ $02.2294^{\prime} \mathrm{W}$ ) during SW06. The areas scanned are $3090 \times 85$ $\mathrm{mm}^{2}$ and $3606 \times 324 \mathrm{~mm}^{2}$ for Site I and II, respectively. The 


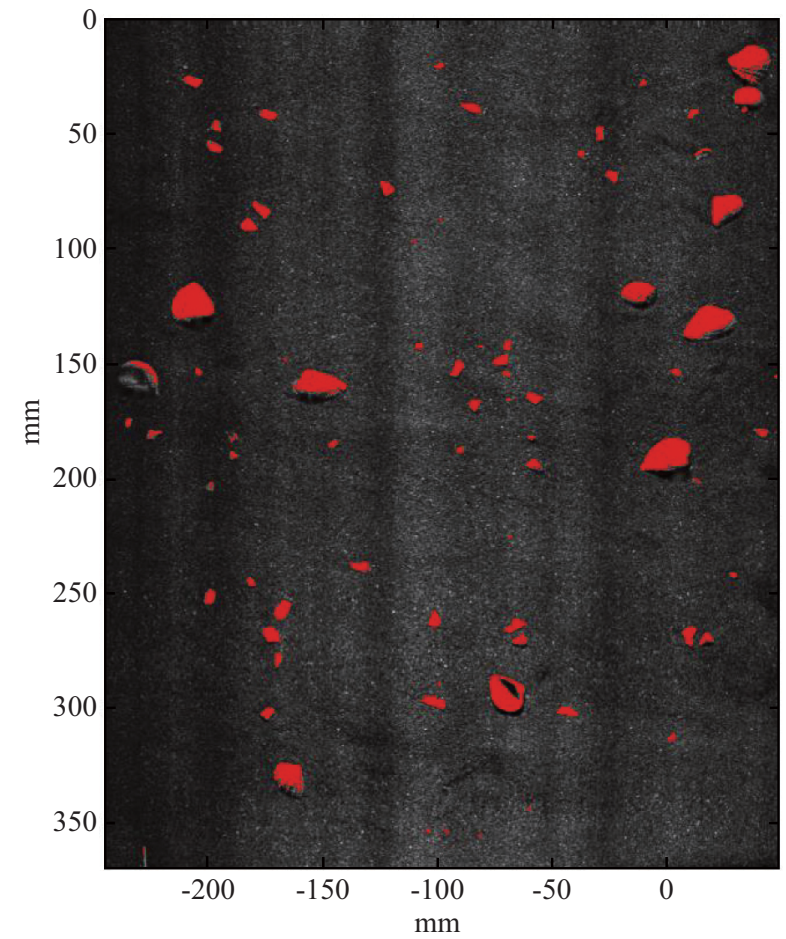

Fig. 9. The superposition of the pixels detected as shell pieces (denoted with red color) on the raw reflection intensity map. All the sixty seven shell pieces in Fig. 6 are detected.

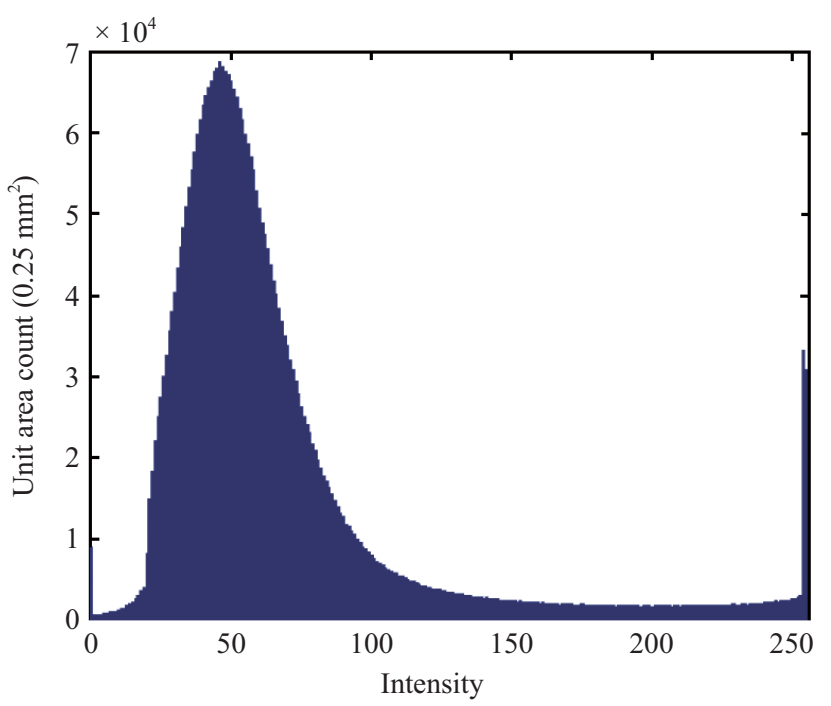

Fig. 10. The reflection intensity histogram of SW06 Site I.

reflection intensity histogram of Site I (Fig. 10) shows a distribution with a major peak at 50 and a narrow and significant peak near 255, beyond which the laser intensity saturates. The narrow peak can be attributed to shells, whereas the main peak is due to scattering from sand. Unlike the laboratory results, there is, there is no clear break between the two peaks. This difference could be due to the presence of small shell pieces
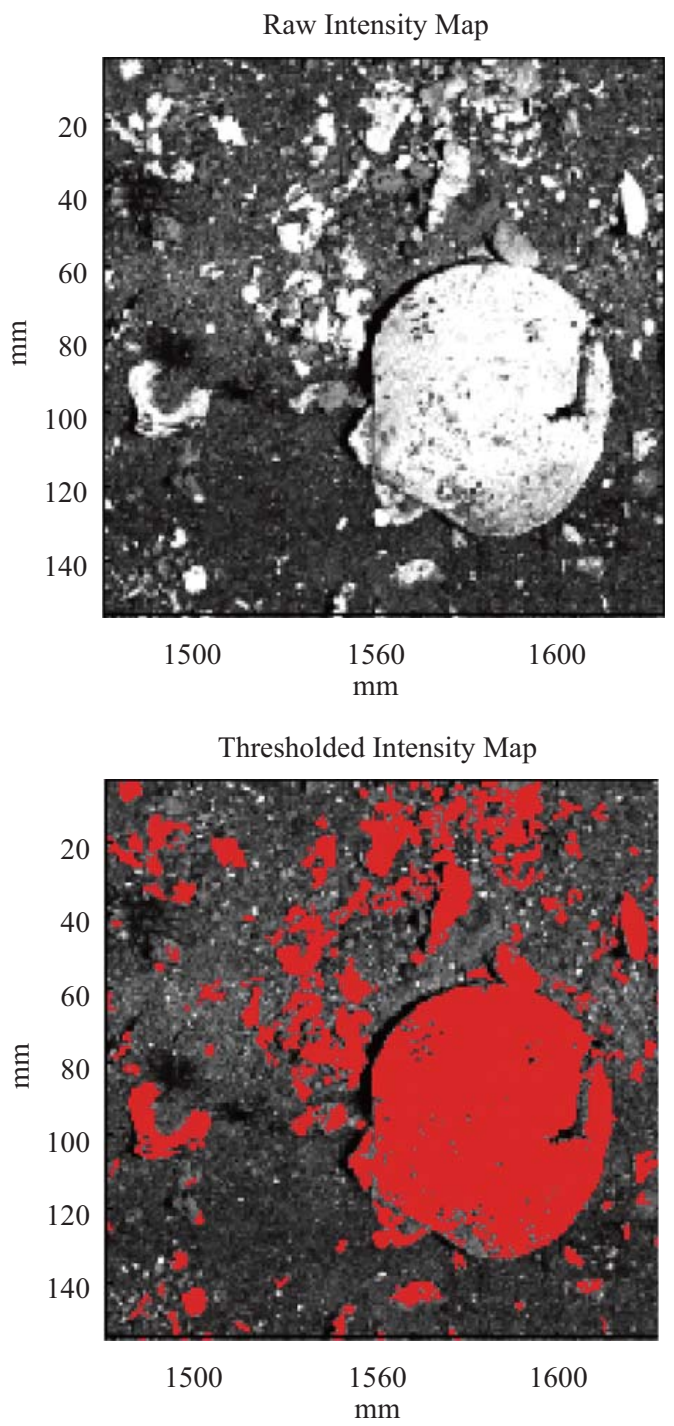

Fig. 11. Detail of the shell detection result for Site I. (Top panel: raw intensity map. Bottom panel: detected shell pieces colored red.)

with sizes similar to sand grains causing the reflectivity to be the result of a combination from sand and shells. Therefore, in addition to applying the threshold as in the laboratory case, another condition was imposed - retain only those shell fragments of size $>4 \mathrm{~mm}^{2}$ and treat smaller fragments as sand particles. In the resulting raw intensity image (Fig. 11, top) contiguous pixels that satisfied both the intensity and size thresholds were marked with red color (Fig. 11, bottom). The planar resolution of the intensity image is $0.5 \mathrm{~mm} \times 0.5 \mathrm{~mm}$, resulting in a unit area of $0.25 \mathrm{~mm}^{2}$, which is used as the base unit of the statistical computation. It was estimated that the overall area coverage by shell fragments $>4 \mathrm{~mm}^{2}$ was $8.53 \%$ for Site I and $6.10 \%$ for Site II. Goff et al. collected nearly 100 grab samples in an area approximately $8 \mathrm{~km}$ northwest of our experiment sites [4]. They report bottom samples collected in locations where shells predominate having a coarse fraction (> $4 \mathrm{~mm}$ ) weight percentage of $5-18 \%$. Though it is difficult 


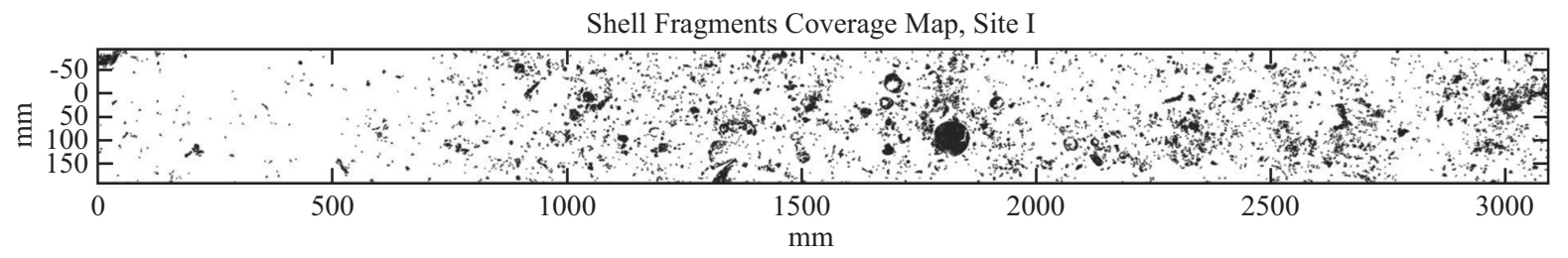

Shell Fragments Coverage Map, Site II

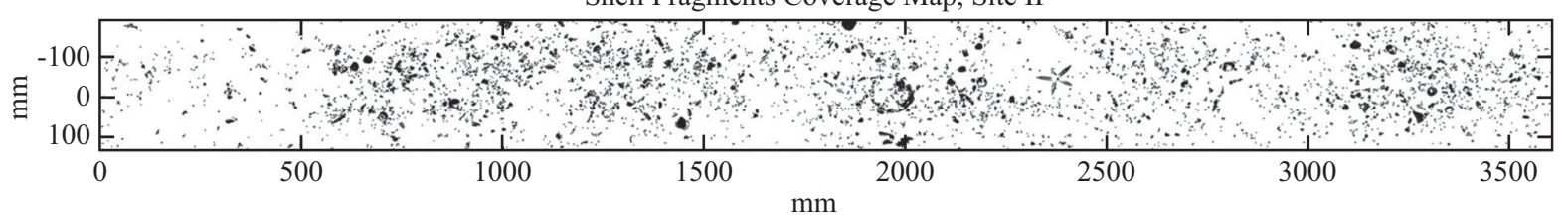

Fig. 12. Shell coverage maps for Site I and II. Dark pixels are areas covered by shell pieces.

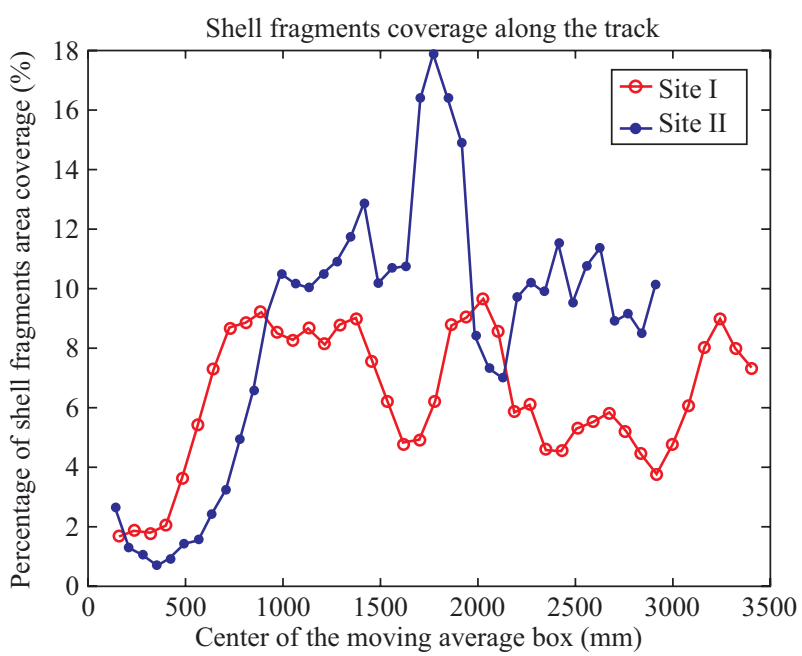

Fig. 13. Percentage of shell area coverage variation along track.

to convert between coarse fraction weight percentage and the area coverage, their results are consistent with those reported here.

Shell fragment spatial variation, shell size distribution, and even shell fragment circumferential lengths can also be assessed from the field data. The laser scanning covered a stripe more than $3 \mathrm{~m}$ long. From the shell coverage images (Fig. 12) the uneven spatial distribution of shells is apparent. To understand the along-track variation of shell fragment coverage, we used a window (a boxcar with full swath as its side, 1/4 overlap) to calculate a moving average of the shell fragment coverage. Plotting the two coverage curves (Fig. 13) reveals that both start with a very low coverage value, about $2 \%$, and then gradually increase until about $800-1000 \mathrm{~mm}$ from the origin. Cross checking between raw intensity images and bathymetry images of both sites revealed that the first $500 \mathrm{~mm}$ of the two sites were smoother than the rest of the scanned areas. This is due to an artificial smoothing during deployment of the IMP2 system: the heavier side of the instrument touched down first with an impact on the seafloor, kicking up sediment, which later settled and covered an area about 500

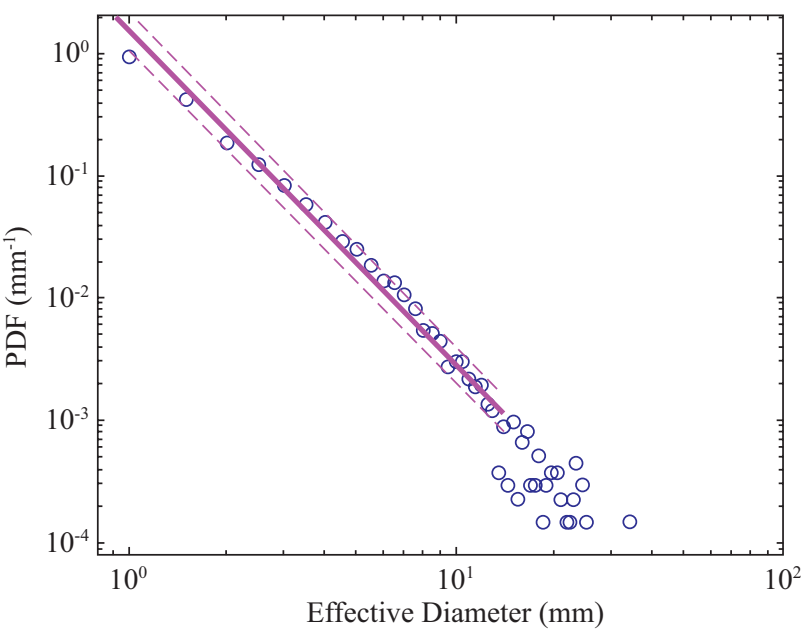

Fig. 14. The probability density functions of shells with effective diameter calculated from two field data sets. The circles are data, the solid line a fit to power-law for shells with sizes up to $15 \mathbf{~ m m}$. The exponent of the power-law fit to the data is $\mathbf{- 2 . 7 3}$. The dashed curves are the one standard deviation error bound of the power-law estimate.

$\mathrm{mm}$ along the track. After excluding this portion of the data, shell fragment area coverage percentage was modified to $9.82 \%$ and $6.80 \%$ for Site I and II, respectively.

The shell sizes were converted to their effective diameters by assuming that all the shells have a circular shape. The size probability distribution functions (PDF) calculated for the two sites are consistent (Fig. 14) and can be approximated by a power-law form:

$$
P(d)=\frac{(\gamma-1)}{d_{1}} \frac{1}{1-\left(\frac{d_{2}}{d_{1}}\right)^{-(\gamma-1)}}\left(\frac{d_{1}}{d}\right)^{\gamma},\left(d_{1}<d<d_{2}\right)
$$

where $d$ is the effective diameter and $d_{1}$ and $d_{2}$ are the smallest and largest respective values of all effective diameters. Here, $d_{1}=2 \mathrm{~mm}$ and $d_{2}=15 \mathrm{~mm}$. Fig. 14 shows the power-law fit to the PDF, where the value -2.73 gives the best fit to the two sets 
of field data, along with plus and minus standard deviation of the error in predicting a future observation. In evaluating the error, we have assumed that errors for different shell sizes are statistically independent. The near power-law distribution implies that the breaking up of shells into fragments is from numerous processes acting on different scales. This PDF combined with area coverage provides a full description of shells on the seafloor if spatial homogeneity of shell distribution is assumed. This result could be used as a starting point to model high-frequency acoustic bottom scattering.

The power-law fit does not apply for shell sizes greater than $15 \mathrm{~mm}$, and the trend for the PDF for large shells is not clear. One reason for this is that there are fewer large shells for the given sample sizes. Another, possibly more important reason is that large, unbroken shells have a size distribution that is not at all power-law distributed. The answer to the size distribution of unbroken shells may be found in the biological literature concerning shell fish species distributions.

\section{SUMMARY}

Motivated by the need to support models of high-frequency acoustic bottom scattering, a simple method to estimate shell size distributions using a laser scanner was developed to analyze the data acquired during SW06. The reflection intensity is closely associated with the textures of bottom features and was used as a primary index to detect shell pieces. When a shell fragment is partially covered by sediment, however, reflection intensity alone does not uniquely define a patch of contiguous pixels to form a feature. To achieve better estimation of the size of a shell fragment, 3D bathymetry and reflection intensity data were integrated and mapped. A laboratory experiment was conducted to validate the reflection intensity method to identify shell pieces on the simulated seafloor and then applied to laser scanning data sets collected during SW06. The area coverage of shell fragments on the seafloor was about $6.80 \%$ and $9.82 \%$ for the two experimental sites. In addition, the size distribution was found to fit a power law PDF. The measured level of shell coverage is expected to impact bottom backscattering at some frequencies.

These results provide inputs to models of high-frequency bottom backscatter. The combined use of the laser scanner and high-frequency backscatter measurements in the same area should lead to a better physical understanding of scattering mechanisms, therefore improve understanding of research problems such as bottom classification. Mounting the laser scanner on an autonomous undersea vehicle on a survey mission would dramatically increase the spatial coverage.

\section{ACKNOWLEDGMENTS}

The laser scanner development was supported by the Taiwan National Science Council (92-2611-E-110-005-CCS), and the Asian Pacific Ocean Research Center, National Sun Yat-sen University; instrument field trials were supported by the Office of Naval Research Ocean Acoustics Program. We thank Po-Chi Chen and Min-Wei Hung at IUT, NSYSU for their technical contribution, and the APL-UW technical staff for the at-sea support.

\section{REFERENCES}

1. Briggs, K. B., "Microtopographical roughness of shallow-water continental shelves," IEEE Journal Oceanic Engineering, Vol. 14, pp. 360-367 (1989).

2. Briggs, K. B., Tang D. J., and Williams, K. L., "Characterization of interface roughness of rippled sand off Fort Walton Beach, Florida," IEEE Journal Oceanic Engineering, Vol. 27, pp. 505-514 (2002).

3. Crawford, A. M. and Hay, A. E., "A simple system for laser-illuminated video imaging of sediment suspension and bed topography," IEEE Journal Oceanic Engineering, Vol. 23, pp. 12-19 (1998).

4. Goff, J., Kraft, B., Mayer, L., Schock, S., Sommerfield, C., Olson, H., Gulick, S., and Nordfjord, S., "Seabed characterization on the New Jersey middle and outer shelf: correlatability and spatial variability of seafloor sediment properties," Marine Geology, Vol. 209, pp. 147-172 (2004).

5. Gonzaleza, R. C., Fu, K. S., and Lee, C. S. G., Robotics: Control, Sensing, Vision and Intelligence, McGraw Hill, New York (1987).

6. Hines, P. C., "Theoretical model of acoustic backscatter from a smooth seabed," Journal of Acoustical Society of America, Vol. 88, pp. 324-334 (1990).

7. Holland, C. W. and Neumann, P., "Sub-bottom scattering: A modeling approach," Journal of Acoustical Society of America, Vol. 104, pp. 13631373 (1998).

8. Ivakin, A. N., "Sound scattering by random inhomogeneities in stratified ocean sediments," Soviet Physics-Acoustics, Vol. 32, pp. $492-496$ (1986).

9. Jackson, D. R. and Briggs, K. B., "High-frequency bottom backscattering: Roughness versus sediment volume scattering," Journal of Acoustical Society of America, Vol. 92, pp. 962-977 (1992).

10. Jackson, D. R. and Ivakin, A. N., "Scattering from elastic sea beds: First-order theory," Journal of Acoustical Society of America, Vol. 103, pp. 336-345 (1998).

11. Jackson, D. R. and Richardson, M. D., High-Frequency Seafloor Acoustics. Springer, New York (2006).

12. Jackson, D. R., Winebrenner, D. P., and Ishimaru, A., "Application of the composite roughness model to high-frequency bottom backscattering," Journal of the Acoustical Society of America, Vol. 79, pp. 1410-1422 (1986).

13. LePage, K. D. and Schmidt, H., "Spectral integral representations of volume scattering in sediments in layered waveguides," Journal of Acoustical Society of America, Vol. 108, pp. 1557-1567 (2000).

14. Lyons, A. P., Akal, T., and Pouliquen, E., "Measurement of seafloor roughness with close range digital photogrammetry," IEEE OCEANS ' 98 Conference Proceedings in CDROM, New York, Vol. 1, pp. 129-133 (1998).

15. Lyons, A. P., Anderson, A. L., and Dwan, F. S., "Acoustic scattering from the seafloor: Modeling and data comparison," Journal of Acoustical Society of America, Vol. 95, pp. 2441-2451 (1994).

16. Lyons, A. P., Fox, W. L. J., Hasiotis, T., and Pouliquen, E., "Characterization of the two dimensional roughness of wave-rippled sea floors using digital photogrammetry," IEEE Journal Oceanic Engineering, Vol. 27, pp. 515-524 (2002).

17. Medwin, H. and Clay, C. C., Fundamentals of Acoustical Oceanography, Academic, Boston (1998).

18. Moore, K. D. and Jaffe, J. S., "Time-evolution of high-resolution topographic measurements of the sea floor using a 3-d laser line scan mapping system," IEEE Journal Oceanic Engineering, Vol. 27, pp. 525-545 (2002).

19. Mourad, P. D. and Jackson, D. R., "A model/data comparison for lowfrequency bottom backscatter," Journal of Acoustical Society of America, Vol. 94, pp. 344-358 (1993).

20. Stanton, T. K. and Chu, D., "On the acoustic diffraction by the edges of benthic shells," Journal of Acoustical Society of America, Vol. 116, pp. 
239-244 (2004).

21. Tang, D., "Fine-scale measurements of sediment roughness and subbottom variability," IEEE Journal Oceanic Engineering, Vol. 29, pp. 929939 (2004).

22. Tang, D., Frisk, G. V., Sellers, C. J., and Li, D., "Low frequency acoustic backscattering by volumetric inhomogeneities in deep-ocean sediments,' Journal of Acoustical Society of America, Vol. 98, pp. 508-516 (1995).

23. Tang, D. and Frisk, G. V., "Spectral parameterization of scattering from a random ocean bottom," Journal of Acoustical Society of America, Vol. 92, pp. 2792-2799 (1992).
24. Tang, D., Jin, G., Jackson, D. R., and Williams, K. L., "Analysis of highfrequency bottom and subbottom backscattering for two distinct shallow water environments," Journal of Acoustical Society of America, Vol. 96, pp. 2930-2936 (1994).

25. Wang, C. C. and Cheng, M. S., "Nonmetric camera calibration for underwater laser scanning system," IEEE Journal Oceanic Engineering, Vol. 32, pp. 383-399 (2007).

26. Wang, C. C. and Tang, D., "Seafloor roughness measured by a laser line scanner and a conductivity probe," IEEE Journal of Oceanic Engineering, Vol. 34, pp. 459-465 (2009) 